\title{
Espoused versus realized knowledge management tool usage in knowledge intensive organizations
}

\author{
Taman H. Powell ${ }^{1}$ \\ Cardiff Business School \\ Cardiff University \\ Aberconway Building \\ Cardiff CF10 $3 E U$ \\ United Kingdom \\ E-mail:powellth@cardiff.ac.uk \\ Tel: +44-2920-870-059
}

\author{
Véronique Ambrosini \\ Monash University \\ Department of Management \\ 900 Dandenong Road \\ Caulfield East \\ Victoria 3145 \\ Australia \\ E-mail:v.ambrosini@monash.edu \\ Tel: +61-3-990-32987
}

${ }^{1}$ Corresponding author. 


\section{Espoused versus realized knowledge management tool usage in knowledge intensive organizations}

Many knowledge intensive organizations (KIOs) have invested in tools and policies to enhance knowledge-sharing and application as this is crucial for their growth. The implementation of these tools results in multiple approaches for knowledge-sharing being available. This article reports on an empirical study of five global management consultancies investigating how consultants choose between these knowledge-sharing alternatives and the factors driving this choice. Our findings indicate that consultants base their decisions on both judging the anticipated benefits of the knowledge content and the associated process costs. Importantly, the criteria employed to assess these knowledgesharing alternatives was different to that of the leadership. The use of different criteria resulted in the leadership championing tools and policies that the consultants did not perceive as valuable. The study contributes to the human resource management and knowledge management literature, not only by surfacing criteria, yet to be discussed in the literature, used by the leadership and consultants of KIOs in determining which knowledge-sharing approach to use, but also by highlighting that when considering KM tools it was critical to take a multi-level approach as there may be some differences in rationales as to why some systems are used or not.

Keywords: leadership, knowledge-sharing, social networks; human resource management; knowledge management; knowledge intensive organizations; consulting. 


\section{Espoused versus realized knowledge management tool usage in knowledge intensive organizations}

\section{Introduction}

Knowledge management (KM) is a key issue in the Human Resource Management (HRM) literature (Cooke, Veen, \& Wood, 2017; Mabey \& Zhao, 2016) given its implications in terms of global talent management (Swart \& Kinnie, 2013), rewards systems (Mabey \& Zhao, 2016), high performance/commitment work practices (Collins \& Smith, 2006), career success (Podolny \& Baron, 1997), innovation performance (Burt, 2004) and team effectiveness (Reagans, Zuckerman, \& McEvily, 2004) to cite just a few.

International HRM scholars have emphasized the importance of knowledgesharing. Knowledge is a critical source of organizational performance and HRM plays a critical role in ensuring that knowledge-sharing happens via for instance structural mechanisms such as the development of communities of practice and training schemes or compensation and performance systems that stimulate sharing (Collins \& Smith, 2006). However despite the increasing attention dedicated to knowledge-sharing, KM efforts are frequently claimed to not deliver on their potential and there is a lack of understanding as to how KM leads to desired outcomes (McIver, Lengnick-Hall, Lengnick-Hall, \& Ramachandran, 2013). It is argued that the term 'KM' may disappear as practitioners rush to disassociate themselves from the relatively unsuccessful effort to use technological solutions (Mabey \& Zhao, 2016).

Scholars highlight different forms of knowledge-sharing in organizational settings. Authors who concentrate on tacit knowledge and conceive knowledge as being rooted in actions, experience and involvement in a specific context (Wenger, 1998) tend to focus on the benefits of social networks as informal knowledge-sharing. Those who 
stress that knowledge is valuable when it is explicit (Bohn, 1994) focus on more formal approaches to KM, approaches that a large number of organizations have adopted in recent years (Powell \& Ambrosini, 2012; Løwendahl, Revang, \& Fosstenløkken, 2001).

Although the literature is replete with studies seeking to understand how knowledge is shared and managed within organizations (Cooke et al., 2017; CameloOrdaz, Garcia-Cruz, Sousa-Ginel, \& Valle-Cabrera, 2011), several issues remain unanswered. First, studies to date have tended to look at social networks or formal KM tools in isolation, not in combination (e.g. Burt, 1997). Knowledge-sharing, however, does not occur in a vacuum. In contexts where there are multiple knowledge-sharing options, perceived benefits and costs for sharing knowledge are likely to play a role in choosing among available approaches. Second, knowledge-sharing is usually investigated top down via interviewing the leadership who mandate the systems (e.g. Hansen, Nohria, \& Tierney, 1999), instead of focusing on the experiences of the practitioners who actually use the systems and share the knowledge. This is problematic, as it does not provide insight into how and why knowledge-sharing approaches are employed by practitioners.

To shed some light on these under-explored areas, we conducted a qualitative study of leadership and users within five knowledge-intensive global consultancy organizations. The leadership being the managers who selected the knowledge-sharing tools to be employed, and the users being the consultants who actually used the tools. Our overarching research objective was to understand how the users, i.e. the consultants in our study, choose among the different knowledge-sharing approaches available to them and illuminate the factors that drive these choices.

The study identified that consultants applied different perceived content benefits and process costs when it came to decide between different $\mathrm{KM}$ approaches than those applied by the leadership. The disconnect, between leadership and 
consultants, in terms of the criteria employed to assess the performance of different knowledge-sharing approaches, led the leadership to implement interventions that further decreased according to the consultants the performance of the knowledge management tools.

The research contributes to the HRM and KM literatures as for both of them knowledge-sharing is a key issue (Kamoche, 1997). We do so, not only by surfacing criteria, yet to be discussed in the literature, used by the leadership and consultants in global KIOs in determining which knowledge-sharing approach to use, but also by highlighting that when considering $\mathrm{KM}$ tools it was critical to take a multi-level approach as there may be some role conflicts (Floyd \& Lane, 2000) which reflect the challenge of 'herding cats' in KIOs (von Nordenflycht, 2010). Identifying the knowledge dimensions that consultants value as a rational explanation for why they do not use KM systems is important. Up to know it has been suggested that they may not want to share their knowledge or are not committed to do so (Camelo-Ordaz et al., 2011). This was suggested by taking the leadership's perspective not that of the consultants. This study is important not only from a contribution to the literature perspective as it brings as just stated much insights into the use of KM systems and the importance of having a multilevel understanding, but also from a practitioner perspective as it brings evidence as to why $\mathrm{KM}$ systems may appear not to work. Indeed, considering both perspectives allows us to make some suggestions, developed in the discussion, as to how HRM interventions can improve KM in KIOs. These include developing structural mechanisms that foster communication, understanding and trust across levels, mentoring and training. Such HRM practices are especially important in international KIOs as social and cultural factors can hamper exchange across hierarchical position. 


\section{Theoretical background}

Much has been written on the nature of knowledge and especially the tacit and explicit dimensions of knowledge (Powell \& Ambrosini, 2012). Tacit knowledge is generally viewed as knowledge that is difficult to express and write down. In contrast, explicit knowledge is knowledge that can be transferred in formal language (Haesli \& Boxall, 2005).

A central debate around the tacit/explicit knowledge types is whether tacit knowledge can be transferred. Much of this debate occurs because the term tacit knowledge is applied to two distinct types of knowledge. Tacit knowledge is described as knowledge embodied in action that represents know-how, which is essentially ineffable. This knowledge needs to be developed by an individual through practice. Tacit knowledge is also used to describe knowledge that could be made explicit but has not been. This knowledge may be particularly complex, or more simply, sufficient time may not have been invested to document this knowledge.

Following Powell and Ambrosini (2012), we will use the terms documented knowledge and undocumented knowledge. The use of these terms is intended to provide distance from the confusion over tacit and explicit knowledge. Documented knowledge is a direct analog for explicit knowledge. Undocumented knowledge is simply knowledge that has not been written down, which can be articulated in a discussion or documented later.

Before knowledge can be shared it needs to be identified (Argote, McEvily, \& Reagans, 2003). Knowledge can be identified in two main distinct ways: via social network or via KM tools (Haas \& Hansen, 2007). Social networks refer to informal relations that exist within teams and across subunits in an organization. There is much research on the use of social networks to access knowledge. These studies have employed social networks to explain career success (Podolny \& Baron, 1997), 
executive compensation (Burt, 1997), innovation performance (Tsai \& Ghoshal, 1998), the creation of intellectual capital (Nahapiet \& Ghoshal, 1998), team effectiveness (Reagans, Zuckerman, \& McEvily, 2004), and the replication of complex and tacit knowledge (Wenger, 1998).

Social networks are generally seen as being beneficial, but they are not without some limitations. Creating social networks takes time and maintaining them is costly due to the need to maintain regular contact with network members (Hansen et al., 2001). These costs limit the number of possible contacts per individual. This in turn reduces the individual's reach in a social network. This means that networks will not be able to access all organizational knowledge, thereby restricting the potential to exploit this valuable resource (Bhalla \& Lampel, 2007).

Aiming to reduce the reliance on social networks, and aid the transfer of knowledge, KM tools have been implemented by the leadership of many organizations and are generally argued to facilitate the rapid identification and transfer of organizational knowledge (Gallupe, 2001). Personalization and codification are two dominant strategies employed in making this happen (Hansen et al., 1999). Both aim to facilitate the sharing of the most appropriate organizational knowledge to the problem at hand. The assumption is that this knowledge is likely to be outside of an individual's social network, and therefore likely to be missed via employing a social network approach to knowledge search (Bhalla \& Lampel, 2007).

The personalization strategy addresses the challenge by developing an index of the location of knowledge in the organization (Kim, Suh, \& Hwang, 2003). This index is often a database, called 'knowledge maps' that allows for expert individuals to be found. This strategy is similar to the social networks' knowledge search. They differ insofar that personalization through KM tools aims to facilitate the contact of the most knowledgeable person for a particular knowledge domain rather than the search being 
limited by the reach of an individual's social network.

The codification strategy approaches the challenge by having individuals document their knowledge and supply it to a central location, generally a searchable KM system (Ofek \& Sarvary, 2001). The logic behind the codification strategy is to make organizational knowledge easily accessible by anyone in the organization, without the need to know or contact the knowledge producer, and thereby achieve scale in knowledge reuse (Hansen et al., 1999).

Therefore, while the personalization strategy facilitates the sharing of knowledge by indicating where the knowledge is, the codification strategy approaches the same challenge by documenting and collecting organizational knowledge in a single location. By generating knowledge encoded in forms, it facilitates its transmission to others. The codification strategy also allows this knowledge to be accessed without having to contact its creator and hence it eliminates any delays linked with contacting the knowledge creator and renders the knowledge into an easily accessible common good (Nielsen \& Michailova, 2007).

Linking the three knowledge-sharing approaches back to knowledge, social networks and knowledge accessed via the personalization strategy relates primarily to undocumented knowledge, while knowledge identified via the codification strategy relates primarily to documented knowledge. We say primarily, as an individual identified via social network or personalization strategy is able to provide both undocumented and documented knowledge. Similarly, the author of a document identified via the codification strategy could also be contacted to provide undocumented knowledge.

Combining these two KM approaches with social networks results in three distinct approaches to sharing knowledge. Knowledge can be shared interpersonally via a social network contact, interpersonally via a colleague identified via a knowledge 
map, and via document identified on a KM system (Powell \& Ambrosini 2012).

All this said one key question needs to be raised: In organizations with multiple approaches for sharing knowledge, what determines how knowledge is actually shared? While there has been much written on knowledge-sharing, research has mainly focused on what approach is being employed by different organizations (e.g., Nielsen \& Michailova, 2007). Yet, there is still sparse research exploring these knowledge-sharing approaches at the practitioner level (Foss, Husted, \& Michailova, 2010). The investigation of which knowledge-sharing approaches practitioners employ, and why they select these approaches should therefore provide useful insights for both academic, and practitioners, especially HRM, audiences.

To extend current theory and create new insights and contribute to the HRM and KIO literature, we designed a study to research how knowledge is shared in environments that provide $\mathrm{KM}$ tools (i.e. $\mathrm{KM}$ systems and knowledge maps) to supplement social networks. Specifically, we examine how the perspective of the leadership and consultants compare in terms of how they evaluate different knowledgesharing approaches. As mentioned, the investigation of the practitioner level perspective in contexts that provide multiple alternatives for knowledge-sharing is lacking. Such an investigation can provide insights in proposing informed HRM interventions as to improve the performance of these knowledge-sharing approaches.

\section{Methodology}

To explore how knowledge is shared in environments providing multiple knowledgesharing approaches, we conducted a series of 44 semi-structured interviews within five management consultancies, four being global. Such open-ended enquiry has been endorsed for explanatory research with the objective of theory development in domains where existing theory is considered nascent (Edmondson \& McManus, 2007). 
Management consultancies were selected for the study as their work is viewed as involving the intensive creation and application of knowledge (von Nordenflycht, 2010). The capability of consultancies depends heavily on their ability to mobilize and synthesize professionalized bodies of expertise in order to create knowledge that satisfies client demands (Løwendahl, 1997). Indeed, McKenna (2006, p. 12) describes consultants as 'pre-eminent knowledge brokers' making them a prime example of global KIOs (von Nordenflycht, 2010). Management consultancies were also among the first to implement organizational KM approaches and generally are viewed as being at the leading edge of KM practice (Løwendahl et al., 2001).

The organizations were selected to represent a range of size, geographic scope (see Table 1), and the research focused on general themes across all organizations to understand the knowledge-sharing processes employed, along with how consultants decide between the available options.

\section{INSERT TABLE 1 ABOUT HERE}

Interviews were conducted with both the leadership and consulting personnel. Leadership interviews focused on the objectives and aims of the KM tools while the consultant interviews focused on knowledge-sharing activities pertaining to a specific project that was completed within the previous 6 months (see Table 2). The objective of interviewing both the leadership and consulting personnel was to understand whether there were differences in perceptions as to the performance of the different approaches of knowledge-sharing.

For each interview, an introductory email was sent by the division head or CEO requesting involvement in the research. In only one instance was involvement refused by an employee. Following from the email, we then called the informant to arrange a 
time and place to conduct the interview. Minimal description of the research was provided prior to the interview to not bias responses. To increase trustworthiness, informants were advised that the research could be discussed at the end of the interview. Interview transcripts were also offered if desired.

\section{INSERT TABLE 2 ABOUT HERE}

Interviews were conducted either at the consultant's office or via telephone. Each interview lasted for approximately one hour and all were recorded. At times, there were discussions about specific clients that could not be divulged, however as the research focused on knowledge processes this was not critical. All interviews followed the same semi-structured outline, which contained a set of questions repeated at each interview (see table 3).

\section{INSERT TABLE 3 ABOUT HERE}

All interviews were transcribed verbatim and analyzed through the qualitative data management software TAMS Analyzer. Our analysis followed an inductive research design, as we continuously iterated and focused our research interest, moving upwards to the level of theoretical generalization. We used 'open coding' (to surface many possible categories), 'axial coding' (to hone categories and articulate properties) and 'selective coding' (to articulate a core category that integrates others into a theory) to code our data.

Open coding involves a free-flow search for themes in the data, which facilitates not only an empirical exploration of these themes but also the need to re-evaluate these emergent themes in the study. Axial coding, on the other hand, involves conceptual 
grouping of the themes in a theoretically meaningful manner. The objective is to identify the themes that tend to converge on a higher-level abstract category (e.g. a 'meta-code'). This enhances the conceptual coherence and the internal validity of the codes. Finally, selective coding consists of associating particular theme combinations with particular groups of subjects in the sample such that a mutually exclusive set of types is created on a sound empirical basis.

While taking an inductive approach means that we were primarily data driven we cannot claim to have started from a 'blank slate' as when we started the analysis we were guided by our research question and the extant literature. This means that as analysis progressed induction overlapped with deduction.

For confidentiality reasons, we omitted the firms and individuals' names concerned.

\section{Findings}

The findings, detailed below, indicate that both the leadership and consultants evaluated knowledge-sharing approaches based on the perceived content benefits less the associated process costs (what we label as 'perceived performance'). While both leadership and consultants considered the benefits and costs, the leadership tended to focus on the benefits associated with the shared knowledge, while consultants tended to focus on the costs associated with the sharing of the knowledge. Additionally, and interestingly, the leadership and consultants concentrated on very different factors when making their assessment of the perceived costs and benefits. These findings were consistent across the five organizations studied, reflecting that many consultancies are similar (von Nordenflycht, 2010). 


\section{The view from the top: Leadership's perspective on costs and benefits}

In our cases the leadership stressed that a key objective of implementing KM tools (i.e. knowledge maps and KM systems) was to improve the reach of knowledge searches and thereby improve the quality of the knowledge shared. As a CKO (Consultancy B) noted: 'some of that works [social networks] ... You know, it's informal. Someone will say, 'I've got a really good proposal from the Germany office last year, let's dust that off and use that.' So that does work, but there could be someone in our Brazil office who didn't get that great proposal from the German office several years ago, so he's missing out on that great proposal'.

There was a belief that 'up to now it [i.e. the organization] was able to function in terms of personal networks ... But now it is getting to the size where that is no longer a tenable model for the firm' (CKO, Consultancy $\mathrm{C})$. This led to a desire to 'start operating as a truly global firm on a less ad hoc basis. So to formalize the processes by which we exchange and share knowledge across the whole firm' (CKO, Consultancy C). The leadership saw formal KM tools as the answer to these problems by providing rapid search with greater reach, and thereby improved knowledge quality.

KM systems were seen as providing significant benefits via allowing consultants to go "with confidence knowing they are going to have all the past experience by client, by industry and by service line available to everyone at the touch of a button' (CKO, Consultancy $\mathrm{C})$. This allowed consultants to 'achieve more in less time ... because we are leveraging vast experience in knowing what pitfalls to avoid' (CKO, Consultancy $\mathrm{C})$. In doing so, $\mathrm{KM}$ systems would replace the use of social networks via providing a tool that would allow for the rapid identification of the most relevant knowledge to the case at hand. As such, the leadership was concentrating on how rapid the search process was, and using the enhanced reach of the search as a proxy for knowledge quality. 
The academic literature also endorses these benefits. It argues that KM systems enable knowledge to be easily shared with other organizational units at close to zero marginal cost (Shapiro \& Varian, 1999). As such, not collecting codified knowledge in such systems was seen as a 'lost opportunity’ (Zack, 1999, p. 47).

Table 4 summarizes the key factors that the leadership considered when they assessed the benefits and costs of the different approaches to sharing knowledge. Essentially the leadership focused on the fact that KM tools provide greater reach by providing access to knowledge beyond that of individuals' social network. In terms of process costs, the leadership focused on the KM system not being dependent upon the responsiveness of colleagues. When colleagues are contacted, there is a preference for the most knowledgeable colleague for the knowledge domain to be identified via a knowledge map, rather than via social networks.

\section{INSERT TABLE 4 ABOUT HERE}

Figure 1 summarizes the performance in terms of content benefit and process cost of each knowledge-sharing approach as perceived by the leadership. The lower left represents low perceived performance (low content benefits and high process costs) while the top right represents high perceived performance (high content benefits and low process costs). The leadership perceived that these tools provide higher quality knowledge as it allows overcoming the limited reach of social networks. They also considered that the KM systems had lower process costs as they removed the delays associated with the access of knowledgeable colleagues.

\section{INSERT FIGURE 1 ABOUT HERE}




\section{Consultants' perspective of knowledge benefits: Recency, relevancy and relationship}

In terms of content benefits, the leadership focused on the reach of the knowledge search as a proxy for knowledge quality. In contrast, the consultants in the study focused on three different factors. These factors were how recent and relevant the knowledge was as well as whether a relationship existed with the knowledge provider. The focus on knowledge with these characteristics led consultants to prefer knowledge from interpersonal sources.

\section{Recent knowledge}

Consultants indicated that knowledge provided interpersonally was more recent than knowledge documented on the KM system. In this regard, KM systems suffer from two perspectives. First, the systems accumulate knowledge that becomes dated. Even with regular purging of knowledge from the systems, the large majority of the knowledge that they contain is not recent. Consultants noted that documents on the knowledge repository were 'not always updated and there are documents in there that are 10 years old' (Consultant, Consultancy D). 'If I was to put "off shoring” into my knowledge exchange database I would probably get all sorts of weird stuff but no decent documents. The stuff would be a bit old, or a bit tatty, so I wouldn't get what I am looking for' (Consultant, Consultancy E).

Second, even in the most conscientious organization, there is a delay before the knowledge is available on the KM system. Knowledge that is in progress is not added until it has been completed. When the knowledge is added it will then need to be reviewed, categorized and sanitized prior to being added to the KM system (sanitizing documents mean removing clients' confidential information.) The KM systems, therefore, become dominated by dated knowledge and do not contain the most recent, 
or in progress, knowledge. Thus, consultants preferred to go to the source and speak directly to the knowledge provider rather than obtain knowledge from the KM system.

\section{Relevant knowledge}

Contacting a knowledgeable colleague was also seen as providing insight as to whether the knowledge was still relevant. 'They can say, well ignore most of the stuff on the database, I think these 3 or 4 documents would be useful. Actually the stuff on the database is an old one, I have a new one that I can send you now... With interpersonal knowledge 'you can ask pointed questions' (Consultant, Consultancy D) and thereby only discuss knowledge relevant to the case at hand. In contrast, documented knowledge is developed prior to the request and it is therefore unlikely for it to be as relevant. Consultants noted that these documents would be 'somewhat tangentially related but not exactly' (Consultant, Consultancy D).

Consultants also claimed that 'there is not much you can learn from them [the documents], they are more output than input' (Consultant, Consultancy D). The documents did not show how they were produced: 'I think the challenge is, moving from showing outputs to actually showing things which actually help people understand how to work' (Consultant, Consultancy D). This was even the case with methodologies that aim to address this process issue: 'The methodology might be written and it is fairly obvious then to a certain extent what needs to be done. But it's the kind of tips and tricks ... if you have just small pointers it can save you so much time' (Consultant, Consultancy D).

\section{Knowledge quality assurance provided by relationships}

One factor that did not explicitly emerge as being sought was extending the reach of the knowledge search to improve the quality of the knowledge content. Instead, 
consultants believed that their history with a colleague provided an indication of quality.

Consultants displayed a distinct preference for interpersonal knowledge. There was, however, the question as to whether this interpersonal knowledge was from members of their social network or whether they employed a knowledge map to identify more relevant colleagues to contact. Consultants noted that the knowledge maps were functional and efficient to use: '[Relevant consultants can be identified] through a KM system that the company has where you can put the name or the methodology, or a thesaurus and it will do a vocabulary search or something and some names will pop up. So one can definitely use that system in order to find out who knows, what they know and what they have done and if they have published things' (Consultant, Consultancy D).

Despite the effectiveness of knowledge maps, consultants noted that they rarely used them. 'I have never used People Find, I've always used my personal network ... I just wouldn't bother [to use the knowledge map] ... I find I generally have a contact somewhere who could tell me somebody else. I think that is the way it works for me' (Consultant, Consultancy E).

Consultants saw their personal networks as being a valuable and important resource for their work: 'I probably know sufficient [consultants] for me to get through the day. That is important' (Consultant, Consultancy D). When prompted, consultants acknowledged that they may not be accessing the most knowledgeable people for the case at hand: 'Are there more people who might have been helpful? Yes, quite possibly. I don't know the answer to that' (Consultant, Consultancy D).

Respondent: I have never used People Find, I've always used my personal network because I know that if they don't know, they will know someone else who does. So what I am doing is tapping into their 
network.

Interviewer: But what if there is a much more knowledgeable person in the organization who is not part of your network?

Respondent: I just don't pick them up, eventually I guess I will. I have trust that I do (Consultant, Consultancy E).

It is self-evident that there could be a better person to talk to regarding the knowledge search. Consultants with particular expertise who were not called upon noted this concern: 'In a way it is problematic. Often a certain team of people have been pulled together and you might then find out that so and so is working on the team and you feel that they should have picked you because you are better qualified ... You want to know: "Why the hell did they pick that person? ... You stupid fools!" (Consultant, Consultancy B).

While the use of social networks in preference to knowledge maps could be due to the belief that consultants felt they had adequate awareness of expert individuals, examples were found where expert consultants volunteered to help other projects but their expertise was still not called upon. 'There was a pure example of that the other day, somebody had done a review of call centers ... I kept saying to them. 'Do you want any help? I know about call centers. Do you want any help?' [They respond:] 'Oh yes, we will get round to it.' And they never managed to have a meeting with me' (Consultant, Consultancy E).

The findings indicated that the awareness of expertise is not the driving factor for knowledge search. Instead, consultants preferred to utilize colleagues whom they had a relationship with. This was highlighted by a consultant as the rationale for why he was selected to assist a project: 'they know me, they know me personally... you just need to go with someone you feel good about' (Consultant, Consultancy, D). We expand upon this in the discussion. 
Essentially, while consultants preferred interpersonal knowledge as it was seen as being more relevant and recent than documented knowledge stored on KM systems, they did not appear to be concerned with potentially gaining knowledge of better quality by going beyond their social network and using a knowledge map. Instead, they chose trusted colleagues from their social network with whom they had a history.

\section{Consultants' perspective of process costs: Response, review and richness}

In terms of process costs, the leadership were primarily concerned with how rapid the knowledge search was but this was not the case of the consultants in the study. In contrast, they focused on the responsiveness of colleagues, the time required to review documents, and the richness of the transfer approach.

\section{Colleagues' responsiveness}

The literature suggests that accessing interpersonal knowledge from colleagues is problematic due to the belief that colleagues are unresponsive and overcoming delays is seen as a key benefit of KM systems as knowledge does not need to be tracked down it is readily available on the KM system (Hansen et al., 1999). Our findings do however provide a different perspective: Colleagues were viewed as being easy to contact in a timely manner and as readily being willing to provide assistance. Colleagues were noted as being 'very helpful, by email or mobile phones you can easily get hold of them' (Consultant, Consultancy D).

In short, one of the purported issues related to interpersonal knowledge-sharing, i.e. that colleagues are not responsive to knowledge requests and are generally reluctant to share their knowledge, did not stand in our study. 


\section{Length of time taken to review documents stored in KM systems}

The consultants found the process of accessing knowledge from the KM systems problematic and they perceived it required significant time and effort to review the identified documents because a large number of documents were stored in these systems. It was questioned whether this investment in time and effort was worthwhile given the uncertainty of finding valuable knowledge. Consultants noted that 'you can go through hundreds of documents and presentations ... [there is] a lot of data on there and you can spend a lot of time without finding anything that really addresses what you are trying to deal with' (Consultant, Consultancy D).

The large size of the knowledge repositories meant that they were seen as being 'useful ... if you have extra time to do some searching through and see if there are some documents that you can get ideas from' (Consultant, Consultancy D). The problem, however, is that consulting 'is a pretty crazy job, people have very limited time' (Consultant, Consultancy D).

In contrast, contacting a colleague was a significantly faster approach to identify knowledge as it reduced the number of documents to review. This was even the case when the knowledge was located on the KM system. Consultants noted that 'it is just a lot quicker to, you know, I can give someone a quick call ... and they can actually direct you to a document maybe that is on the database and addresses that specific question. So instead of spending 3 or 4 days trawling through this database I find it is quicker to have a quick conversation with someone' (Consultant, Consultancy D).

The leadership had a significantly different perspective as to the process costs related to the KM systems. They viewed the systems as being highly efficient, with knowledge available 'at the touch of a button' (CKO, Consultancy C). While it is undoubtedly correct the consultants found it was very time consuming to review this knowledge and determine its relevance to the case at hand. The leadership did not 
consider this review time.

Essentially, while the leadership believed that 'quality goes up, problems are fewer because we are leveraging vast experience in knowing what pitfalls to avoid. ... So that people are able to achieve more in less time' (CKO, Consultancy $\mathrm{C})$, the reality was that the vast amounts of knowledge on the systems were not seen as warranting the significant effort required to review the identified documents. The potential incremental quality achieved through reviewing and 'leveraging vast experience' was not seen as worth the effort when compared to the other available approaches.

\section{Richness and efficiency of interpersonal knowledge transfer}

Interpersonal communication was also preferred from a knowledge transfer perspective. The richness of interpersonal knowledge transfer was seen as providing valuable feedback and non-verbal communication, which improved the accuracy of knowledge transfer. 'The great advantage of getting two people eyeballing each other is you can tell probably whether I am understanding what you are saying.... You get some idea as well whether I am talking a load of crap or not. You can make those sorts of judgments. Much of the valuable information I believe is stuff which cannot be easily transmitted unless you have got that degree of feedback going on all the time' (Consultant, Consultancy E).

Interpersonal communication was not seen as being substitutable by other approaches to knowledge transfer. 'Despite all the media that is available to us, and by that I'm thinking, voicemail, email, webcasts, the phone, internal communication. Somehow, things often get lost in translation. You can't really beat face-to-face discussion with any of those methods' (Consultant, Consultancy D). As another consultant noted: 'I just find it easier to grasp an approach if somebody tells it to me ... if you speak to someone and then I look at slides, they don't tell you what happened' 
(Consultant, Consultancy D).

The advantages of interpersonal transfer in terms of colleagues being responsive, reviewing being minimized, and the richness of transfer resulted in lower process related costs for the knowledge searcher. As a result, consultants employed this approach in preference to KM systems.

Table 5 summarizes the key factors that consultants consider when assessing the costs and benefits of the different approaches. They perceived that social networks provide recent and relevant knowledge transferred in a rich manner that minimizes review. While the leadership focused on KM tools increasing the reach of a knowledge search as a proxy for improving quality of the knowledge transferred, consultants relied on their relationships with social network contacts as a proxy for quality.

\section{INSERT TABLE 5 ABOUT HERE}

The content benefit and process cost characteristics that the consultants focused on resulted in the perceived performance of different knowledge-sharing approaches depicted in Figure 2. In this figure, the lower left represents low perceived performance (low content benefits and high process costs) while the top right represents high perceived performance (high content benefits and low process costs).

\section{INSERT FIGURE 2 ABOUT HERE}

Significantly, as consultants employed different criteria for both content benefits and process costs, they had a divergent perspective from the leadership as to the perceived performance of the different knowledge-sharing approaches (Figure 1). 


\section{Discussion and conclusion}

The study set out to investigate how consultants evaluated and selected between knowledge-sharing alternatives in global KIOs. In doing so we shed light on the criteria employed to assess the costs and benefits of knowledge-sharing employing different approaches and as such contributed to the HRM, KM and KIO literature (von Nordenflycht, 2010). Our study has provided a nuanced understanding on why KM tools are championed and the evaluation of the performance criteria of these tools by not only revealing what the basis for the choice is and what these criteria were but also by bringing to the fore that there was significant divergence in perception between the leadership and consultants. As such this extends the HRM literature regarding the barriers to knowledge transfer by providing an additional explanation (e.g. other than lack of commitment or lack of trust) as to why knowledge is not shared.

The leadership, who were responsible for the KM systems implementation, focused on increased reach and rapid search. In contrast, consultants focused on recent, relevant knowledge from colleagues with an existing relationship in terms of content benefits, and the responsiveness of colleagues, minimal review and richness of transfer in terms of process costs. This divergent focus led the leadership and consultants to have very different perspectives on the perceived performance of different knowledgesharing approaches. The leadership viewed KM systems and knowledge maps to be superior to social networks, while consultants believed the converse. The concern of the leadership with the use of social networks is that these networks are limited, may not include the most knowledgeable person for the query at hand, and are costly. This view seems to find support in literature advocating the benefits of explicit knowledge (Hansen et al., 1999). The findings also indicate that in identifying knowledgeable colleagues, consultants displayed a strong preference for social networks rather than knowledge maps. This was so despite that consultants recognized the ability of the 
knowledge maps to identify knowledgeable colleagues. Even in cases where colleagues outside of a social network volunteered to help on a project, they were frequently not called upon. These findings seem to mirror the literature on tacit knowledge, which highlights the importance of relational embeddedness (Granovetter, 1985) as well as trust and identification (Nahapiet \& Ghoshal, 1998) for knowledge-sharing to occur. It may also give credence to the claim that, given the dominance of relationships for knowledge-sharing, competence may be irrelevant (Casciaro \& Lobo, 2008).

The divergent beliefs of the leadership and consultants posed challenges for knowledge-sharing in practice. While the leadership recognized that KM tools were underutilized, this did not cause them to question their belief in their superiority. Instead, low utilization was seen as a result of insufficient knowledge being contributed to KM systems. This knowledge supply issue was considered to be due to the consultants' reluctance to share their knowledge (Camelo-Ordaz et al., 2011). Overcoming this reluctance is frequently put forward as the key challenge associated with KM and 'herding cats' in KIOs (von Nordenflycht, 2010). This metaphor encapsulates the challenge of managing KIO employees. The essentially intellectually skilled KIO workforce has a strong sense of autonomy and a distaste for direction, supervision and formal organizational processes. This means that HRM practices need to bring about a supportive and collaborative climate and develop a compensation system that rewards knowledge-sharing (Collins \& Smith, 2006; Swart \& Kinnie, 2013).

The KIOs in our study adopted this knowledge supply focus and provided knowledge-sharing incentives: "what we need to do is to establish the right behaviors across the whole business globally. [...] obviously getting compliance up and running as we launch the system is key [...] we expect $100 \%$ compliance rather than letting people slip through the net if they don't really feel like doing it. Similarly establishing 
a certain level of quality and consistency throughout rather than; "Oh well, we will just throw something in there and tick the box"” (CKO, Consultancy $\mathrm{C})$.

To address the 'herding cats' challenge and engender willingness to contribute knowledge to the KM system the leadership argued that such contributions provided a good medium for self-promotion via the showcasing of work. The leadership tried nudging and persuading (Malhotra, Morris, \& Hinings, 2006) rather than commanding and playing on the fact that reputation is key to consultants (Greenwood, Li, Prakash, \& Deephouse, 2005). The leadership argued that 'from a purely selfish aspect there are very compelling reasons to get your name out there to everyone in the globe to say look this is the fantastic work I am doing' (CKO, Consultancy $\mathrm{C})$. If this was not sufficient motivation, participation in terms of contribution was often tracked and participation enforced: 'if people want to try and back out we are not going to let them because we will have matrix in place to see who are the people who are not playing ball' (CKO, Consultancy C). These actions can be viewed as the leadership implementing human resource interventions to 'motivate' the consultants to use the KM tools (Cabrera \& Cabrera, 2005; Haesli \& Boxall, 2005). While it is clear that human resource practices are an important factor for the adoption and use of KM tools (Camelo-Ordaz et al., 2011) our research shows that such interventions are insufficient when the tools are not viewed as being useful in themselves.

These findings resonate with the literature on managers' strategic roles (e.g. Floyd \& Lane, 2000) insofar that these differences in foci reflect the predominant aspect of the leadership role that is decision making and the predominant aspect of middle managers that is implementing (Mantere, 2008). The roles influence the type of information looked for and the behavior (Floyd \& Lane, 2000). Consultants are primarily concerned with making things happen and getting the job done, hence their decision criteria of recency, relevance and quality reflect their role orientation. 
Recognizing and understanding the different role between the leadership and the consultants should allow for the differences in perceptions to be discussed and resolve any conflicts. This means that communication between the two groups is essential. This suggests that one HRM priority (Maybe \& Zhao, 2016) is to develop structural mechanisms within KIOs such as communities where both leadership and consultants attend and discuss their role. Mentoring of consultants may also be an avenue as it facilitates understanding, facilitate exchanges and develop trust (Collins \& Smith, 2006). This process of developing role specific knowledge will be a first step in recognizing that it is not that consultants do not want to share their knowledge but that they have a different view as to what knowledge-sharing should be about. This is especially critical in international KIOs as social and cultural factors may be a hindrance to informal relationship and exchange across formal position (Reiche, 2011). It also reinforces the critique that too many HR efforts about knowledge exchange have taken a top down approach and hence have not been conducive to knowledge transfer from employees (Mabey \& Zhao, 2016). This is one aspect of the HRM literature that is under-studied and with our study we have shown that the leadership and practitioners i.e. here management consultants are critical to understand how the performance of KM tools is determined and as a corollary why some tools are used rather than others. It highlights one of the determinants of why knowledge-sharing may not happen that has not been discussed in the literature, and hence we contribute to the HRM field as knowledge-sharing is a key HRM issue (Kamoche, 1997; Cooke et al. 2017). These theoretical insights also allow us to caution similarly to Mabey, Kulich, and LorenziCioldi (2012) that the international HRM practice of sometimes over-promoting technology as a knowledge-sharing mechanism. It also empirically supports the challenge described by McIver et al. (2013) that investing in KM systems is not always a good option as based on our findings they may not be used a great deal or their users 
may not perceive them to be performing appropriately.

\section{Managerial implications and further research}

The unrecognized inter-level dissensus that we saw in our study leads to some significant managerial and HRM implications. Table 6 provides a summary of the strengths and weaknesses of the knowledge-sharing approaches along with some suggested interventions that leadership may deploy to improve the performance of each approach.

INSERT TABLE 6 ABOUT HERE

Our findings suggest different actions to improve the performance of knowledge-sharing approaches. The perceived performance of KM systems was hindered largely due to there being large quantities of knowledge on the systems that resulted in significant time and effort being required to review this knowledge. The findings suggest that these systems should be managed with a focus on knowledge demand rather than knowledge supply. This is in line with recent research (Powell \& Ambrosini, 2012) which indicates that the content on KM systems needs to be actively overseen. Contributed knowledge should be novel when compared to the knowledge existing on the KM system and this knowledge should be sufficiently demanded to justify the contribution, both in terms of the work associated in contributing the knowledge as well as the impact the additional knowledge will have on search and review performance. The findings also suggest that knowledge should be documented and contributed only if it is sufficiently durable to warrant the effort. A removal strategy should also be employed to remove outdated knowledge. This could be part of the training and development of consultants. HRM practices should not only be about 
training consultants about how the KM systems function but also about encouraging consultants to signal what they believe is redundant knowledge that needs to be removed. The preference for the use of social networks, despite their limited nature, suggests that there is an opportunity for interventions by the leadership that target the development of these networks. Research has started to address this area via focusing on the impact of organizational design and HRM practices (Moreno-Luzón \& Begoña Lloria, 2008), personnel characteristics and profiling (Cabrera et al., 2006), people management (Cabrera \& Cabrera, 2005), recruitment and retention (Haesli \& Boxall, 2005), job rotation (Kane, Argote, \& Levine, 2005), project team composition (Reagans, Zuckerman, \& McEvily, 2004), and client project selection (Løwendahl et al., 2001). The outcome of such interventions is however uncertain (Thompson, 2005). This study, through the identification of factors that influence the perceived content benefits and process costs of knowledge-sharing approaches across organizational levels, provides some guidelines for informed organizational responses to this dissensus and the herding cats challenge. Our proposed HRM interventions have the potential to improve knowledge-sharing in the workplace, something that is key for modern organizations.

\section{Limitations}

The limits of qualitative research involving a small set of cases are well documented, and it would not be possible to make any empirical generalization (to the population) from these findings. However as argued, many KIO organizations share similar characteristics (von Nordenflycht, 2010) and hence the findings and their implications are likely to be relevant and transferrable to other KIOs. Given the lack of literature to contextualize knowledge processes in KIOs, this in-depth case study research affords the opportunity to develop insights regarding these complex processes. We were also 
unable to discuss our findings with the KIOs but it would also have been insightful to explore the leadership and the consultants' reactions as to provide further richness to our study. 


\section{References}

Argote, L., McEvily, B., \& Reagans, R. (2003). Managing knowledge in organizations: An integrative framework and review of emerging themes. Management science, 49, 571-582.

Bhalla, A., \& Lampel, J. (2007). Let's get natural: The discourse of community and the problem of transferring practices in knowledge management. Management Decision, 45, 1069-82.

Burt, R. (1997). The contingent value of social capital. Administrative Science Quarterly, 42, 339-65.

Burt, R. (2004). Structural holes and good ideas. American Journal of Sociology, 110, 349-99.

Cabrera, A., Collins, W., \& Salgado, J. (2006). Determinants of individual engagement in knowledge sharing. The International Journal of Human Resource Management, 17, 245-264.

Cabrera, E., \& Cabrera, A. (2005). Fostering knowledge sharing through people management practices. The International Journal of Human Resource Management, 16, 720-735.

Camelo-Ordaz, C., Garcia-Cruz, J., Sousa-Ginel, E., \& Valle-Cabrera, R. (2011). The influence of human resource management on knowledge sharing and innovation in Spain: The mediating role of affective commitment. The International Journal of Human Resource Management, 22, 1442-1463.

Casciaro, T., \& Lobo, M. (2008). When competence is irrelevant: The role of interpersonal affect in task-related ties. Administrative Science Quarterly, 53, $655-84$.

Collins, C., \& Smith, K. (2006). Knowledge exchange and combination: the role of 
human resource practices in the performance of high-technology firms. The Academy of Management Journal, 49, 544-560.

Cooke, F., Veen, A. \& Wood, G. (2017). What do we know about cross-country comparative studies in HRM? A critical review of literature in the period of 2000-2014. International Journal of Human Resource Management, 28, 1-72.

Edmondson, A., \& McManus, S. (2007). Methodological fit in management field research. Academy of Management Review, 32, 1155-79.

Floyd, S., \& Lane, P. (2000). Strategizing throughout the organization: Managing role conflict in strategic renewal. Academy of Management Review, 25, 154-177

Foss, N., Husted, K., \& Michailova, S. (2010). Governing knowledge sharing in organizations: Levels of analysis, governance mechanisms, and research directions. Journal of Management Studies, 47, 455-82.

Gallupe, B. (2001). Knowledge management systems: Surveying the landscape. International Journal of Management Reviews, 3, 61-77.

Granovetter, M. (1985). Economic action and social structure: The problem of embeddedness. American Journal of Sociology, 91, 481-510.

Greenwood, R., Li, S., Prakash, R., \& Deephouse, D. (2005). Reputation, diversification, and organizational explanations of performance in professional service firms. Organization Science, 16, 661-673.

Haas, M., \& Hansen, M. (2007). Different knowledge, different benefits: Toward a productivity perspective on knowledge sharing in organizations. Strategic Management Journal, 28, 1133-53.

Haesli, A., \& Boxall, P. (2005). When knowledge management meets HR strategy: An exploration of personalization-retention and codification-recruitment 
configurations. The International Journal of Human Resource Management, 16, 1955-1975.

Hansen, M., Nohria, N., \& Tierney, T. (1999). 'What's your strategy for managing knowledge?. Harvard Business Review, 77, 106-16.

Kamoche, K. (1997). Knowledge creation and learning in international HRM. International Journal of Human Resource Management, 8, 213-225.

Kane, A., Argote, L., \& Levine, J. (2005). Knowledge transfer between groups via personnel rotation: Effects of social identity and knowledge quality. Organizational Behavior \& Human Decision Processes, 96, 56-71.

Kim, S., Suh, E., \& Hwang, H. (2003). Building the knowledge map: An industrial case study. Journal of Knowledge Management, 7, 34-45.

Løwendahl, B. (1997). Strategic management of professional service firms. Copenhagen: Copenhagen Business School Press.

Løwendahl, B., Revang, O., \& Fosstenløkken, S. (2001). Knowledge and value creation in professional service firms: A framework for analysis. Human Relations, 54, 911-31.

Mabey, C., Kulich, C., \& Lorenzi-Cioldi, F. (2012). Knowledge leadership in global scientific research. International Journal of Human Resource Management, 23, $2450-2467$.

Mabey, C. \& Zhao, S. (2016). Managing five paradoxes of knowledge exchange in networked organizations: new priorities for HRM? Human Resource Management Journal, 26, 1-19.

Malhotra, N., Morris, T., \& Hinings, C. (2006). Variation in organizational form among professional service organizations. Research in the Sociology of Organizations, 
24, 171-202.

Mantere, S. (2008). Role expectations and middle manager strategic agency. Journal of Management Studies, 45, 294-316.

McKenna, C. (2006). The world's newest profession: Management consulting in the twentieth century. Cambridge: Cambridge University Press.

McIver, D., Lengnick-Hall, C., Lengnick-Hall, M., \& Ramachandran, I. (2013). Understanding work and KM from a knowledge-in-practice perspective. Academy of Management Review, 38, 597-620.

Moreno-Luzón, M., \& Begoña Lloria, M. (2008). The role of non-structural and informal mechanisms of integration and coordination as forces in knowledge creation. British Journal of Management, 19, 250-76.

Nahapiet, J., \& Ghoshal, S. (1998). Social capital, intellectual capital, and the organizational advantage. Academy of Management Review, 23, 242-66.

Nielsen, B., \& Michailova, S. (2007). Knowledge management systems in multinational corporations: Typology and transitional dynamics. Long Range Planning, 40, 314-40.

Ofek, E., \& Sarvary, M. (2001). Leveraging the customer base: Creating competitive advantage through knowledge management. Management Science, 47, 1441-56.

Podolny, J., \& Baron, J. (1997). Resources and relationships: Social networks and mobility in the workplace. American Sociological Review, 62, 673-93.

Powell, T., \& Ambrosini, V. (2012). A pluralistic approach to knowledge management practices: Evidence from consultancy companies. Long Range Planning, 45, 209-26.

Reagans, R., Zuckerman, E., \& McEvily, B. (2004). How to make the team: Social 
networks vs. demography as criteria for designing effective teams. Administrative Science Quarterly, 49, 101-33.

Reiche, B. (2011). Knowledge transfer in multinationals: The role of inpatriates' boundary spanning. Human Resource Management, 50, 365-389.

Shapiro, C., \& Varian, H. (1999). Information rules: A strategic guide to the network economy. Boston, MA: Harvard Business School Press.

Swart, J. \& Kinnie, N. (2013). Managing multidimensional knowledge assets: HR configurations in professional service firms. Human Resource Management Journal, 23, 160-179.

Thompson, M. (2005). Structural and epistemic parameters in communities of practice. Organization Science, 16, 151-64.

Tsai, W., \& Ghoshal, S. (1998). Social capital and value creation: The role of intrafirm networks. Academy of Management Journal, 41, 464-76.

von Nordenflycht, A. (2010). What is a professional service firm? Toward a theory and taxonomy of knowledge-intensive firms. Academy of Management Review 35, $155-174$.

Wenger, E. (1998). Communities of practice: Learning, meaning, and identity. Cambridge: Cambridge University Press.

Zack, M. (1999). Managing codified knowledge. Sloan Management Review, 40, 4558. 
Bohn, R. (1994). Measuring and Managing Technological Knowledge. Sloan Management Review, 35, 61-74.

Hansen, M., Podolny, J., \& Pfeffer, J. (2001). So many ties, so little time: A task contingency perspective on the value of social capital in organizations. In S. M. Gabbay and A. J. Leenders (Eds.), Social Capital of Organizations (pp. 21-58). New York: JAI Press. 
Figure 1. Knowledge sharing performance (leadership perspective).

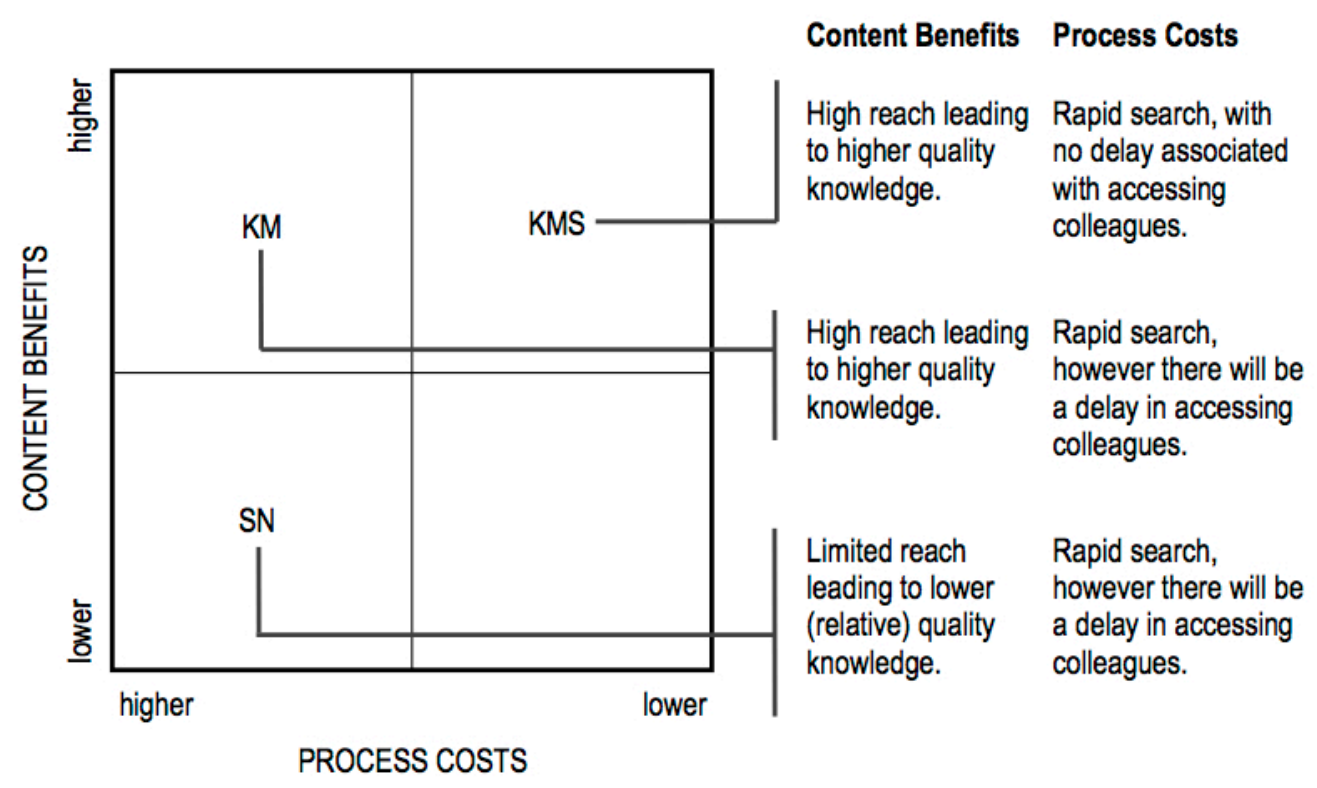

\section{Legend}

KMS: knowledge management system

$\mathrm{KM}$ : knowledge map

SN: social network 
Figure 2. Knowledge sharing performance (consultant perspective).

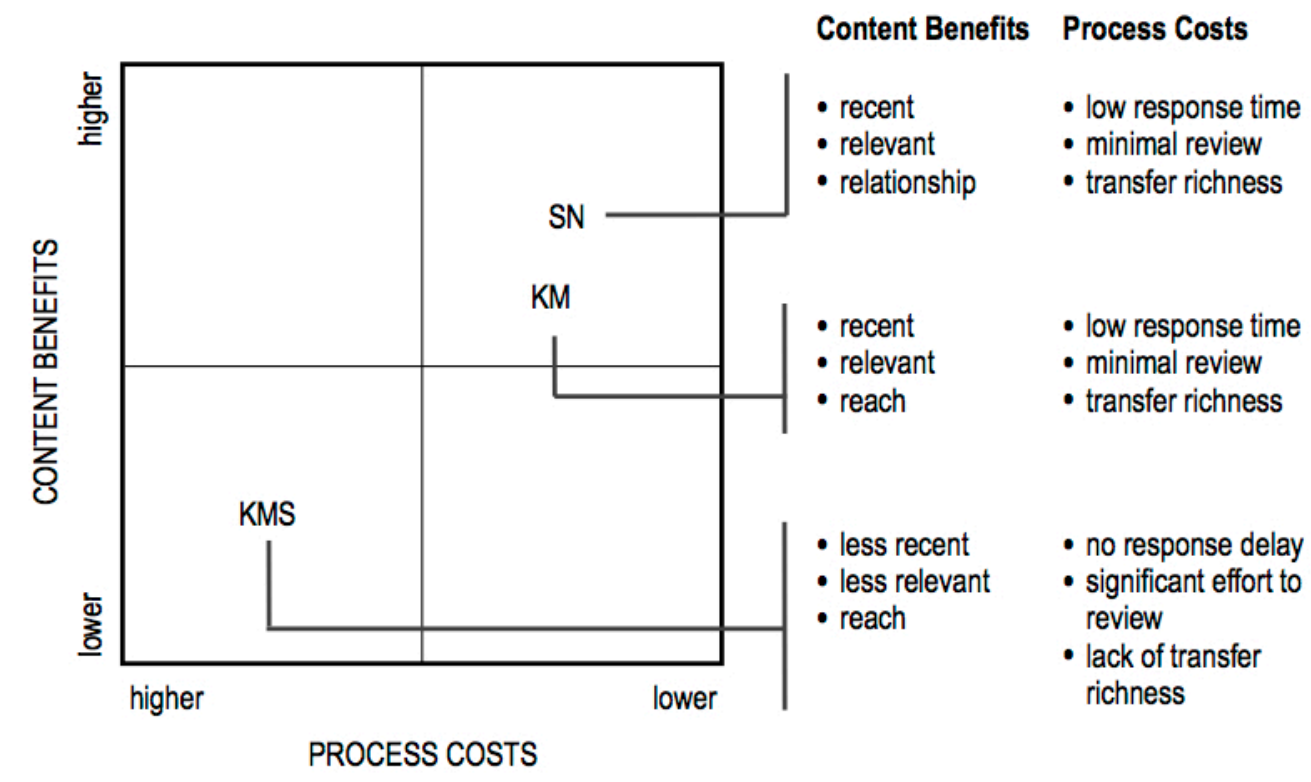

Legend

KMS: knowledge management system

$\mathrm{KM}$ : knowledge map

SN: social network 
Table 1. Overview of organizations studies.

\begin{tabular}{lrrrrr}
\hline & A & B & C & D & E \\
\hline UK Offices & 1 & 5 & 1 & 1 & 41 \\
Global Employees & 30 & 2,500 & 600 & 800 & 12,000 \\
Global Offices & 1 & 94 & 16 & 28 & 771 \\
Leadership (CKO/Knowledge & 1 & 1 & 5 & 1 & 70 \\
Managers) & 30 & 300 & 80 & 100 & 800 \\
UK Consultants & & & & & \\
\hline
\end{tabular}


Table 2. Interview matrix.

\begin{tabular}{|c|c|c|c|c|c|c|}
\hline & & $\mathbf{A}$ & B & $\mathbf{C}$ & D & $\mathbf{E}$ \\
\hline $\begin{array}{l}\text { Leadership } \\
\text { Managers) }\end{array}$ & (CKO/Knowledge & 2 & 1 & 3 & 1 & 6 \\
\hline Consultants & & 9 & 4 & 4 & 10 & 4 \\
\hline Total & & 11 & 5 & 7 & 11 & 10 \\
\hline
\end{tabular}


Table 3. Examples of the questions asked to leadership and consultants.

- The importance of knowledge to the organization (for instance, 'How important do you consider knowledge to your organization?')

- Whether formal approaches for KM tools implemented (for instance, 'Have you implemented any tools to aid in knowledge use and management?')

- The objective of the KM tools (for instance, 'What was the objective behind the tools that you implemented?')

- The characteristics of the project (for instance, 'Can you outline briefly the project objectives and the related time line?', 'Was the project challenging to you in terms of the objective and the time line?')

- The characteristics of the project (for instance, 'Can you outline briefly the project objectives and the related time line?', 'Was the project challenging to you in terms of the objective and the time line?')

- The characteristics of the knowledge used (for instance, 'Did you use any knowledge on the project from the wider organization?', 'What type of knowledge did you use?')

- How the knowledge was found (for instance, 'How did you identify these documents?', 'Why did you employ this approach?') 
Table 4. Knowledge sharing factor assessment (leadership perspective).

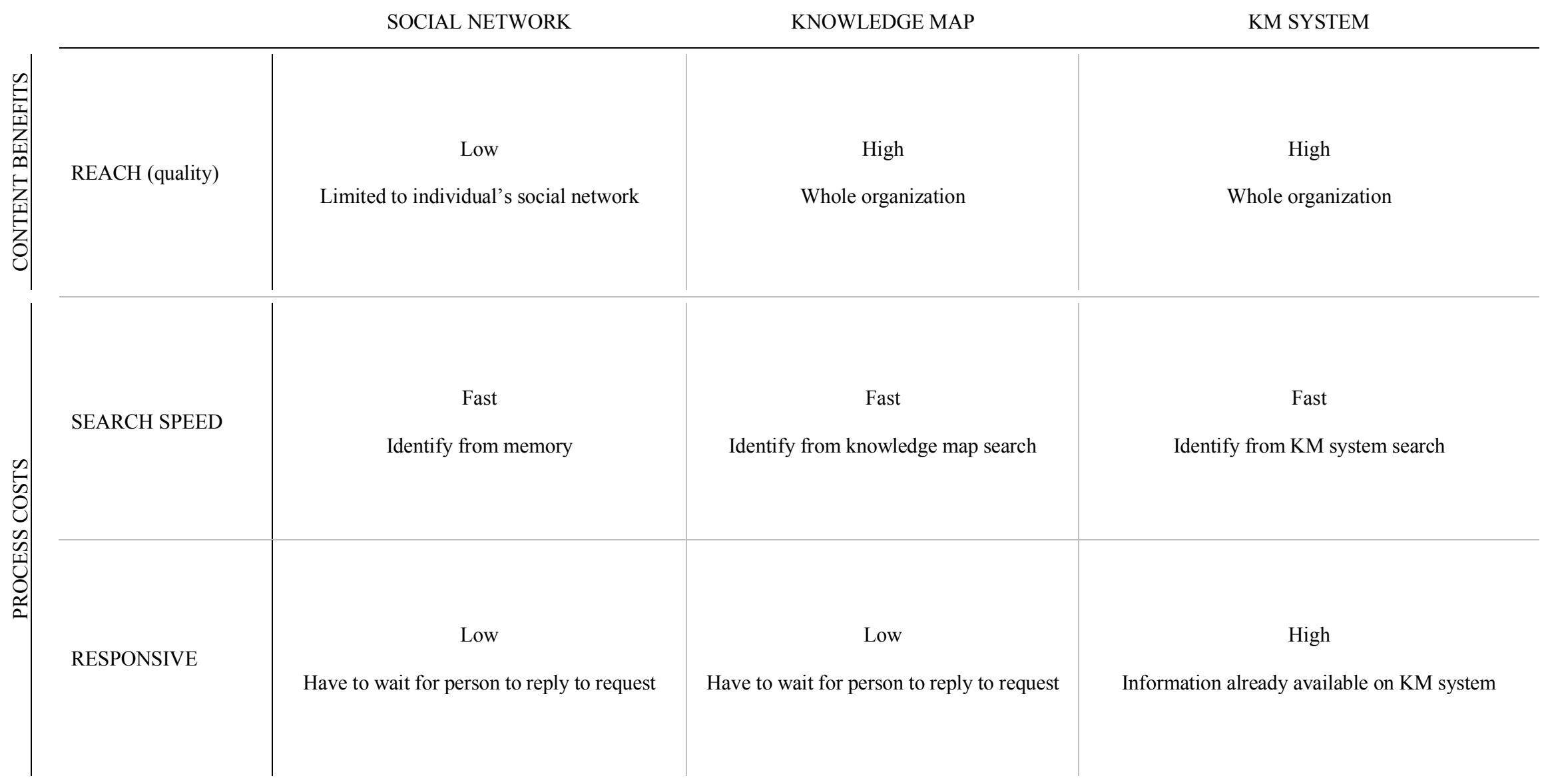


Table 5. Knowledge sharing factor assessment (consultant perspective).

\begin{tabular}{|c|c|c|c|}
\hline & SOCIAL NETWORK & KNOWLEDGE MAP & KM SYSTEM \\
\hline RECENT & $\begin{array}{c}\text { Recent } \\
\text { Only most current knowledge }\end{array}$ & $\begin{array}{c}\text { Recent } \\
\text { Only most current knowledge }\end{array}$ & $\begin{array}{l}\text { Not Recent } \\
\text { Both current and historical knowledge }\end{array}$ \\
\hline RELEVANT & $\begin{array}{l}\text { Relevant } \\
\text { Knowledge provided customized to request }\end{array}$ & $\begin{array}{l}\text { Relevant } \\
\text { Knowledge provided customized to request }\end{array}$ & $\begin{array}{l}\text { Less Relevant } \\
\text { Knowledge provided prior to knowing specific } \\
\text { knowledge required }\end{array}$ \\
\hline RELATIONSHIP & $\begin{array}{c}\text { Relationship } \\
\text { Knowledge provider known by knowledge } \\
\text { requestor }\end{array}$ & $\begin{array}{l}\text { No Relationship } \\
\text { Knowledge provider unknown by knowledge } \\
\text { requestor }\end{array}$ & $\begin{array}{c}\text { No Relationship } \\
\text { Knowledge provider unknown by knowledge } \\
\text { requestor }\end{array}$ \\
\hline RESPONSIVE & $\begin{array}{c}\text { Responsive } \\
\text { Colleagues seen as being responsive to } \\
\text { requests }\end{array}$ & $\begin{array}{c}\text { Responsive } \\
\text { Colleagues seen as being responsive to } \\
\text { requests }\end{array}$ & $\begin{array}{c}\text { Responsive } \\
\text { KM system always available }\end{array}$ \\
\hline REVIEW & $\begin{array}{c}\text { Minimal Review } \\
\text { Information provided selectively based on } \\
\text { knowledge request }\end{array}$ & $\begin{array}{c}\text { Minimal Review } \\
\text { Information provided selectively based on } \\
\text { knowledge request }\end{array}$ & $\begin{array}{l}\text { Significant Review } \\
\text { Information returned from KM system can be } \\
\text { substantial }\end{array}$ \\
\hline $\begin{array}{l}\text { RICHNESS of } \\
\text { TRANSFER }\end{array}$ & $\begin{array}{c}\text { Rich Transfer } \\
\text { Two-way communication allows for } \\
\text { customized nuanced transfer }\end{array}$ & $\begin{array}{l}\text { Rich Transfer } \\
\text { Two-way communication allows for } \\
\text { customized nuanced transfer }\end{array}$ & $\begin{array}{l}\text { Not Rich Transfer } \\
\text { Reading of documented knowledge does not always } \\
\text { "say" the important facts }\end{array}$ \\
\hline
\end{tabular}


Table 6. Leadership knowledge sharing interventions.

SOCIAL NETWORK

KNOWLEDGE MAP

KM SYSTEM

\begin{tabular}{|c|c|}
\hline STRENGTHS & $\begin{array}{l}\text { Two-way transfer allows for knowledge } \\
\text { provision to be customized to the case at hand. } \\
\text { - Rich knowledge transfer improves fidelity. } \\
\text { Knowledge provided from trusted colleague } \\
\text { provides quality assurance. } \\
\text { History with colleague facilitates very efficient } \\
\text { knowledge transfer. } \\
\text { Trusted relationship facilitates transfer of off- } \\
\text { the-record knowledge. }\end{array}$ \\
\hline WEAKNESSES & $\begin{array}{l}\text { - Limited reach leads to probable sub-optimal } \\
\text { knowledge sharing. } \\
\text { - Requires contact with knowledge provider. } \\
\text { - Interpersonal transfer can take significant time } \\
\text { and effort for knowledge provider if knowledge } \\
\text { is in high demand. }\end{array}$ \\
\hline ADVICE & $\begin{array}{l}\text { - Conduct interventions to actively influence the } \\
\text { social network structure of the organization. } \\
\text { Encourage other tools to be used in } \\
\text { conjunction. }\end{array}$ \\
\hline
\end{tabular}

- Aids in identifying the most knowledgeable person for a particular knowledge domain.

- Two way transfer allows for knowledge

provision to be customized to the case at hand.

- Rich knowledge transfer improves fidelity.

- No requirement to contact knowledge producer.

- Efficient, from knowledge provider perspective, when knowledge is in high demand.

- Protects knowledge against attrition.

- Difficult to classify the knowledge of people.

- Requires contact with knowledge provider.

- Lack of history between knowledge searcher and provider makes assessment of knowledge quality more challenging.

- Lack of history with colleague can make communication less efficient

- Interpersonal transfer can take significant time and effort for knowledge provider if knowledge is in high demand.

- Facilitate the development of a common company language (e.g. common training, networking events).

- Employ knowledge maps as a tool to construct beneficial social networks.

- Accept that knowledge maps will be used as a secondary approach vis-à-vis social networks and $\mathrm{KM}$ systems.
- $\quad$ Large amounts of knowledge requires significant time to review.

- Knowledge not customized to case in hand.

- Much of the knowledge is redundant and out of date.

- Does not contain in-progress, or just completed, knowledge.

- Employ only for knowledge in high demand.

- Reduce review time via actively managing the amount of knowledge on the system - only contribute novel and durable knowledge that is sufficiently demanded.

- Actively remove outdated and low demand knowledge. 